\title{
Reducing demand for overexploited wildlife products: Lessons from systematic reviews from outside conservation science
}

\author{
Douglas MacFarlane $^{1,2} \quad$ | Mark J. Hurlstone ${ }^{2,3}$ (i) | Ullrich K. H. Ecker ${ }^{2}$ | \\ Paul J. Ferraro ${ }^{4}$ | Sander van der Linden ${ }^{5}$ (i) | Anita K. Y. Wan ${ }^{6}$ | \\ Diogo Veríssimo $^{7,8}$ (i) | Gayle Burgess ${ }^{9}$ | Frederick Chen ${ }^{10}$ ｜ Wayne Hall ${ }^{11}$ | \\ Gareth J. Hollands $^{12}$ ｜ William J. Sutherland ${ }^{1,13}$ \\ ${ }^{1}$ Conservation Science Group, Department of Zoology, University of Cambridge, Cambridge, UK \\ ${ }^{2}$ School of Psychological Science, University of Western Australia, Crawley, Western Australia, Australia \\ ${ }^{3}$ Department of Psychology, Lancaster University, Lancaster, UK \\ ${ }^{4}$ Carey Business School and the Department of Environmental Health and Engineering, A Joint Department of the Bloomberg School of Public \\ Health and the Whiting School of Engineering, Johns Hopkins University, Baltimore, Maryland, USA \\ ${ }^{5}$ Department of Psychology, Social Decision-Making Laboratory, University of Cambridge, Cambridge, UK \\ ${ }^{6}$ Socio-Ecological and Conservation Science Laboratory, School of Life Sciences, Sun Yat-Sen University, Guangzhou, Guangdong, China \\ ${ }^{7}$ Oxford Martin Program on the Illegal Wildlife Trade, Oxford University, Oxford, UK \\ ${ }^{8}$ Department of Zoology, University of Oxford, Oxford, UK \\ ${ }^{9}$ TRAFFIC, The Wildlife Trade Monitoring Network, Cambridge, UK \\ ${ }^{10}$ Department of Economics, Wake Forest University, Winston-Salem, North Carolina, USA \\ ${ }^{11}$ National Centre for Youth Substance Use Research, University of Queensland, Brisbane, Queensland, Australia \\ ${ }^{12}$ Behaviour and Health Research Unit, University of Cambridge, Cambridge, UK \\ ${ }^{13}$ BioRISC, St. Catharine's College, Cambridge, UK
}

\section{Correspondence}

Mark J. Hurlstone, Department of Psychology, Lancaster University, Lancaster, UK.

Email: m.hurlstone@lancaster.ac.uk

\begin{abstract}
Conservationists have long sought to reduce consumer demand for products from overexploited wildlife species. Health practitioners have also begun calling for reductions in the wildlife trade to reduce pandemic risk. Most wildlifefocused demand reduction campaigns have lacked rigorous evaluations and thus their impacts remain unknown. There is thus an urgent need to review the evidence from beyond conservation science to inform future demandreduction efforts. We searched for systematic reviews of interventions that aimed to reduce consumer demand for products that are harmful (e.g., cigarettes and illicit drugs). In total, 41 systematic reviews were assessed, and their data extracted. Mass-media campaigns and incentive programs were, on average, ineffective. While advertising bans, social marketing, and location bans were promising, there was insufficient robust evidence to draw firm
\end{abstract}


conclusions. In contrast, the evidence for the effectiveness of norm appeals and risk warnings was stronger, with some caveats.

\section{K E Y W O R D S}

behavior change, biodiversity conservation, demand reduction, evidence-based interventions, fear appeals, illegal wildlife trade, mass-media campaigns, overconsumption, social norms, zoonoses

\section{1 | INTRODUCTION}

The overexploitation of wild animals, plants, and fungi is a major driver of biodiversity decline (Maxwell, Fuller, Brooks, \& Watson, 2016; Rosen \& Smith, 2010). In addition to directly depleting population numbers, overexploitation can affect the balance of predator and prey species within food webs and diminish the productivity of important human food sources. For example, the global shark-fin industry, driven primarily by Asian demand for shark-fin soup (Dulvy et al., 2014), is an important cause of declining shark populations (Clarke, Milner-Gulland, \& Bjørndal, 2007). Sharks play a crucial role in maintaining ecosystem health, and their overexploitation dramatically restructures marine-life communities, which in turn, has been linked to the collapse of fishing industries (Brierley, 2007; Myers, Baum, Shepherd, Powers, \& Peterson, 2007).

A major driver of overexploitation is the wildlife trade, which comprises a diverse set of actors, ranging from suppliers that hunt and transport products, to consumers who buy and trade them through tourist markets, exotic pet forums, and other means. Consumer demand for wildlife products such as rhino horn, pangolin scales, and bat meat (Suwannarong \& Schuler, 2016) can threaten biodiversity in complex ways. For example, the international trade in wildlife can facilitate the global spread of infectious wildlife diseases (Kolby, 2016) such as the amphibian chytrid fungus, which is spread through the amphibian trade and has already caused more extinctions than any other pathogen in recorded history (Scheele et al., 2019).

Beyond its alarming environmental impacts, the illegal and unethical aspects of the wildlife trade can have devastating effects on human communities by accelerating government corruption (Wittig, 2016) and militarizing conservation responses (Crayne \& Haenlein, 2016; Duffy \& Humphreys, 2016). The wildlife trade has likely contributed to the emergence of several major human disease outbreaks, including at least two novel coronavirus outbreaks in the last two decades (Cyranoski, 2020). Virologists have consistently warned that the highest risk of virulent zoonotic spillovers comes from the mixing of taxonomically diverse species and increased humananimal interaction (Johnson et al., 2015, 2020) that are ubiquitous in the wildlife trade.

The traditional response to the overexploitation of wildlife has been to attempt to reduce supply via international trade bans and regulations under the Convention on International Trade in Endangered Species of Wild Fauna and Flora. Whilst there is some evidence that trade bans can be effective when accompanied by other measures (Kasterine \& Lichtenstein, 2018), they can have adverse impacts. For example, trade bans can increase demand among consumers who believe the resource may soon be unavailable, driving price hikes that incentivize illegal poaching (e.g., bush meat and black rhinoceros; Cronin et al., 2015; Leader-Williams, 2014). This can also occur when a product ban is poorly enforced and demand is inelastic, which incentivises traders to supply markets illegally and use force to control the market (Challender, Hinsley, \& Milner-Gulland, 2019; Heltberg, 1999).

Given these limitations, conservationists increasingly want to complement supply side interventions with actions to reduce consumer demand such as public communications and awareness-raising campaigns to counter the illegal wildlife trade (Wright, Bhammar, Gonzalez Velosa, \& Sobrevila, 2016). However, fundamental questions remain about which campaigns are the most effective in reducing consumer demand for overexploited (also illegal or unethical) wildlife products. Are awareness-raising campaigns effective for changing consumer behavior? Are positively framed messages more effective than negative ones? Can incentives provide sustainable consumer behavior change? Is social marketing a key to halting overconsumption? Does banning location-based consumption, such as China's ban on shark-fin soup at government banquets ( $\mathrm{Ng}, 2013)$, reduce overall consumption, or merely displace it? The present overview seeks to provide novel insight into these questions.

Unfortunately, the evidence on the impact of interventions aiming to alter the behavior of wildlife consumers is largely anecdotal or based on weak research designs with a high risk of bias, such as pre-post studies without control comparisons. A recent review by 
Veríssimo and Wan (2019) identified 236 demandreduction campaigns aimed at wildlife products but found only five that reported direct changes in consumer behavior. Furthermore, only two campaigns reported behavioral outcomes that allowed estimates of variability and effect sizes. The authors concluded the absence of robust evaluations precluded meaningful recommendations to inform future action. There is urgent need for empirical evidence to increase the likelihood that future demand-reduction campaigns are effective and efficient, and do not have counterproductive effects.

To fill this knowledge gap, we examine the broader literature on "what works" in reducing consumer demand for products that are harmful to health, society, or the environment. Since most demand-reduction campaigns are intended to counter behaviors that cause such harms, we confined our search criteria to interventions that target products considered harmful (e.g., alcohol, cigarettes, unhealthy foods). This multidisciplinary approach is important for two primary reasons. First, compared to conservation, greater resources have been devoted to testing behavior-change interventions to reduce harmful consumer demand in health, criminology, and education (Kidd, Bekessy, \& Garrard, 2019b; Leigh, 2018; Pynegar, Gibbons, Asquith, \& Jones, 2021). Consequently, there is more robust evidence on the effectiveness of interventions targeting harmful consumer demand in disciplines other than conservation. Second, there is little reason to suggest this situation is likely to change. Until conservation organizations adopt experimental (or robust quasi-experimental) designs to test behavior-change interventions

T A B LE 1 Possible demand parallels between wildlife products and other harmful products

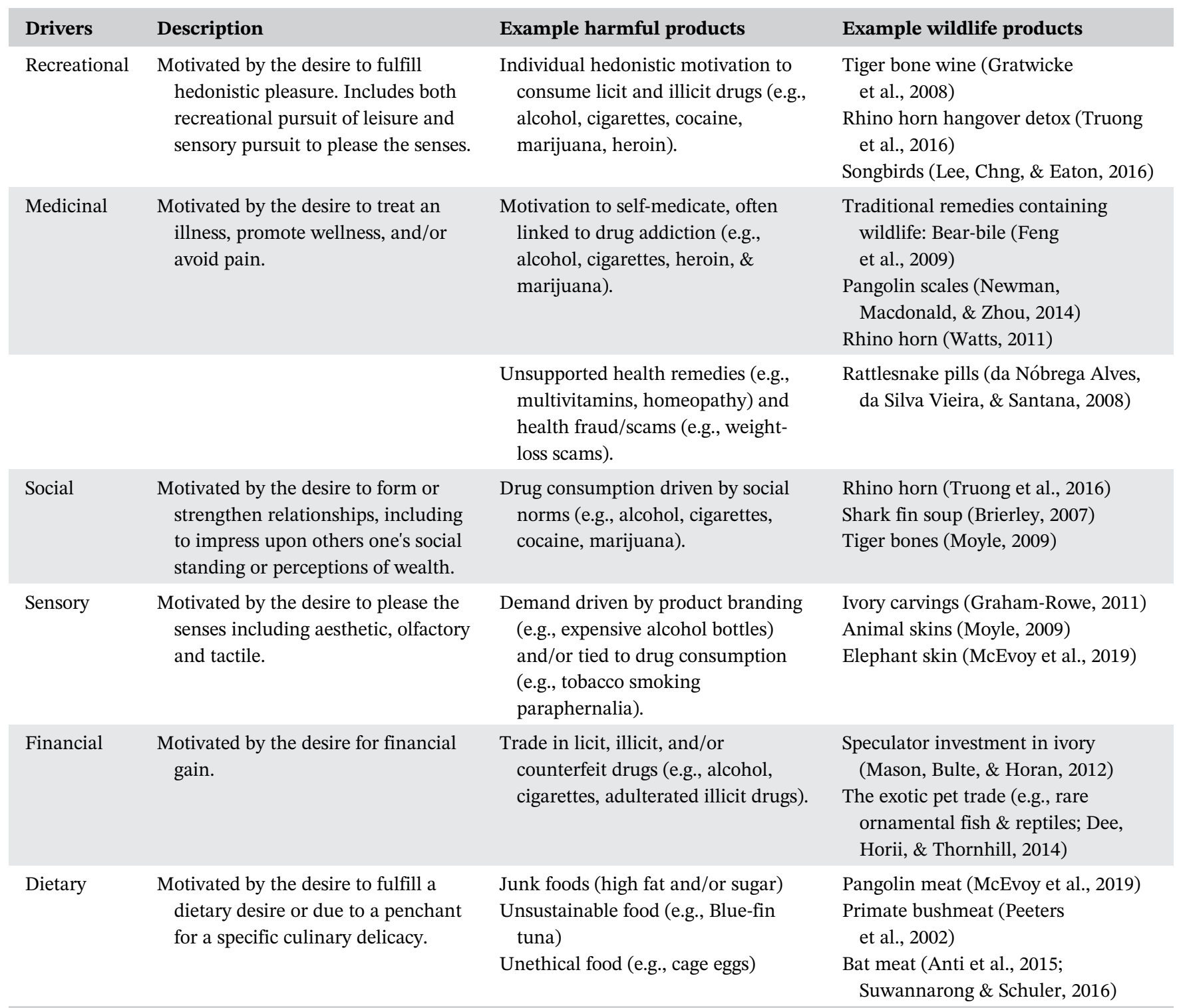

Note: The driver categories and subsequent descriptions have been adapted from recent work by Thomas-Walters et al. (2021) to categorize motivations for wildlife consumer products. 
(Bayliss, Haddaway, Eales, Frampton, \& James, 2016; Kidd, Bekessy, \& Garrard, 2019a), it will be difficult to determine which strategies are effective, ineffective, or harmful.

Our aim was to synthesize evidence on demandreduction interventions targeting products that may have parallels with the wildlife trade (i.e., sharing similar consumer motivations, such as the desire for recreation or social recognition; Table 1). We acknowledge that consumer dynamics of nonwildlife products will inevitably differ in ways that may limit the generalisability of the results to conservation (e.g., alcohol is cheap, accessible, and mostly legal, whereas rhino horn is expensive, harder to source, and often illegal). However, conceptually similar underlying consumer motivations (Table 1) and analogous approaches to demand-reduction campaigns provide a sufficient basis to estimate the potential effectiveness of commonly used behavioral interventions.

The demand-reduction campaigns that are the subject of our review were primarily designed to reduce demand for products that are harmful to the health of the user. While many wildlife products carry considerable health risks (e.g., bush meats have been linked to infectious diseases), we recognize that many others do not (e.g., ivory), which may thus limit the generalizability of the conclusions drawn from our analysis pertaining to such products. However, if we assume that people prioritize their own welfare over other issues, then finding that a strategy is ineffective at reducing demand for a product that is harmful to health suggests the same strategy will also be ineffective at reducing demand for products that are nonharmful to health. Thus, our focus on products that are harmful to health is justifiable as it may help determine the upperbound for effectiveness of strategies to reduce demand for wildlife products that are nonharmful to health.

\section{2 | METHODS AND RESULTS}

We formed an advisory board of experts in health, psychology, social marketing, economics, and conservation to inform our search strategy. The advisory board generated a list of relevant terms to initiate the literature search (Supplementary Search Strategy and Table S1). We began with a systematic search of the Cochrane Library, followed by a systematic search of the Web of Science, PsychINFO, and Scopus platforms. We then manually retrieved any additional citations either suggested by the advisory board or identified by backwards citation searching from included studies. To provide a manageable overview of the vast body of evidence, we imposed several eligibility criteria (Supplementary Eligibility Criteria and Table S2). Chief among these was that we limited our analysis to systematic reviews or meta-analyses of interventions to reduce demand for a harmful product using quantitative data visà-vis intervention effectiveness that were judged by the research team to be relevant to wildlife products and related behaviors. The final list of included articles contained 41 systematic reviews, of which 16 contained metaanalyses. Data were extracted from reviews using a standardized form that collected information regarding the outcome indicators assessed, results of any meta-analysis, study limitations, and a summary of the authors' conclusions (Supplementary Data Extraction and Table S3).

Reviews were categorized into seven broadly defined intervention types: mass-media campaigns, incentives, advertising bans and regulations, social-marketing campaigns, location-based bans, norm appeals, and risk warnings (this taxonomy of intervention types emerged whilst conducting the data screening and extraction, since they were common approaches assessed by the systematic reviews). Reviews were assessed according to quality (Supplementary Quality Assessment), with 12 rated as Quality A (no limitations identified); 13 as Quality B (one limitation identified); and 16 as Quality C (two or more limitations identified). We assessed reviewer agreement across each review-quality criterion individually with a reliability analysis using Cohen's $\kappa$ (Supplementary $\kappa$ Analysis). Mean percentage agreement was $88 \%$ and average $\kappa=0.63(\kappa>0.6=$ substantial agreement; McHugh, 2012). Individual criteria with $\kappa<$ 0.6 were revisited for discussion and reconciliation. Only one criterion (Supplementary $\kappa$ Analysis) failed to meet this benchmark $(\kappa=0.22)$. Subsequently, four instances of disagreement were revisited and some additional limitations were noted. The reconciliation process did not change the overall review-quality ratings, as most disagreements related to low-quality reviews with several other limitations.

Narrative summaries of each systematic review are provided next (for more detailed information, see Table S3). Reviews under each intervention category are ordered by review quality, date, and name of first author. Number of studies included in each systematic review is denoted via $k$. When reviews provided information on experimental design of included studies, we provide this information using the following abbreviations: RCT, randomized control trial; ITS, interrupted time series; NRSI, nonrandomized studies of interventions; BA, before/ after; L, longitudinal; Obs, observational.

\section{1 | Mass-media campaigns}

This category included initiatives that used mass-media communication to persuade people to change their behavior. A typical example was a campaign that ran advertisements at cinemas to challenge perceptions about smoking. 
Nine systematic reviews focused on the impact of mass-media campaigns, mostly on drug consumption (illicit drugs, alcohol, and tobacco). Review Quality A: Carson-Chahhoud et al. (2017, $k=8,7$ RCT, 1 ITS) noted most (five of eight) studies found no effect of mass-media campaigns on preventing youth smoking. However, they concluded it would be unwise to draw firm conclusions due to inconsistent results and risk of bias in study designs and methods. Mosdøl, Lidal, Straumann, \& Vist, (2017, $k=6$, 5 RCT, 1 ITS) concluded that their confidence in the impact of mass-media campaigns on multiple behaviors (including tobacco and alcohol consumption) in ethnic minorities was very low because most studies were of low quality. Allara, Ferri, Bo, Gasparrini, \& Faggiano, (2015, $k$ $=19,8 \mathrm{RCT}$ ) found no effect of mass-media campaigns on illicit drug use in eight studies, evidence of beneficial effects in four studies, and evidence of maladaptive effects in two studies. They concluded it is not possible to draw general conclusions due to paucity and inconsistency of available evidence. Review Quality B: Bala, Strzeszynski, \& Topor-Madry, (2017, $k=11$, NRSI) concluded comprehensive tobacco control programs may change smoking behaviors in adults, but noted evidence came from a small number of very low quality studies. Trieu et al. (2017, $k=22$, 4 RCT) found population-level mass-media campaigns can reduce salt consumption, but higher-quality studies showed smaller effect sizes and inconsistent results, so they concluded that mass-media campaigns are likely ineffective. Werb et al. (2011, $k$ $=11,7 \mathrm{RCT}, 4 \mathrm{Obs}$ ) found only one of seven RCTs found evidence that public-service announcements reduce illicit drug use and two found evidence that they increased usage. A meta-analysis of eligible RCTs showed no significant effect. Observational studies revealed evidence of beneficial and harmful effects. Review Quality C: Allen et al. (2015, $k=34$, NRSI) concluded there was strong evidence supporting use of mass-media campaigns to reduce youth smoking. Durkin, Brennan, \& Wakefield, (2012, $k=26$, NRSI) concluded the effectiveness of mass-media campaigns on reducing youth smoking depended on campaign reach, intensity, duration, and messaging used-communicating negative health effects was most effective at encouraging quitting. Snyder et al. (2004, $k=21$, mostly NRSI) concluded that mass-media health campaigns have only small measurable effects on tobacco and alcohol consumption over the short term.

\subsection{Incentives}

These interventions inform participants that they will receive future benefits if they adopt a desired health behavior (e.g., smoking cessation). Incentives included contests, competitions, incentive schemes, lotteries, raffles, and contingent payments. An example is the smokefree class competition, which involves asking students to enter into a contract not to smoke for a set period and promises of prizes for classes that stay mostly (>90\%) smoke-free.

Three systematic reviews focused on the impact of incentive campaigns (e.g., contests and lotteries) in smoking behaviors. Review Quality A: Corepal, Tully, Kee, Miller, \& Hunter, $(2018, k=8$, RCT) concluded that incentives have a small impact on reducing smoking in children and adolescents (5-18 years). Mantzari et al. (2015, $k=34$, RCT) concluded that financial incentives can be effective for smoking cessation for up to 18 months, but effects did not persist beyond 3 months after their removal. Review Quality B: Hefler, Liberato, \& Thomas, (2017, $k=8$, 3 RCT) concluded the small number of studies suggested incentive programs did not prevent smoking initiation.

\section{3 | Advertising bans}

This category includes bans or restrictions on advertising to promote the consumption of harmful products, such as cigarettes or alcohol. Bans could cover, for example, advertising on television, internet, or billboards. Another common example is legislation requiring cigarettes to be sold in plain-packaging to remove the colorful and attractive branding used in product promotion.

Six systematic reviews focused on the impact of advertising bans on cigarette and alcohol consumption. Review Quality B: McNeill et al. (2017, $k=51,1$ RCT) concluded that plain cigarette packaging may reduce consumption, noting that evidence was mostly based on one large observational study in Australia $(N=700,000)$. Siegfried et al. (2014, $k=4,1$ RCT, 3 ITS) concluded that the quality of evidence was too low to support a ban on alcohol advertising. Review Quality C: Hughes, Arora, \& Grills, $(2016, k=4)$ concluded that there is insufficient evidence from low-income countries to draw firm conclusions about the impact of plain packaging on cigarette consumption. Moodie et al. (2012, $k=37,2$ RCT) found the evidence for impact of plain packaging on cigarette consumption was mixed but suggested it had a deterrent effect. Capella, Taylor, \& Webster, $(2008, k=50)$ concluded that cigarette advertising bans (both full or partial, e.g., only in broadcast media) did not have a significant impact on cigarette consumption. Quentin, Neubauer, Leidl, \& König, (2007, $k=24$, NRSI) found in 10 of 24 studies that full-advertising bans had a significant effect on cigarette consumption, but noted significant limitations in drawing conclusions from time-series data. 


\subsection{Social marketing}

Social marketing is broadly defined as the use of marketing techniques to achieve positive social ends (Carins \& Rundle-Thiele, 2014). Although social-marketing campaigns can utilize mass-media, the approach differs from mass-media campaigns (as broadly defined in the present article) by encouraging adoption of other intervention approaches such as education, social initiatives (e.g., designated driver campaigns), and counseling (e.g., quit lines and cessation groups). Social marketing is commonly conceived as a process in which intervention design is guided by key marketing principles such as customer orientation, market segmentation, and motivational exchange (increasing incentives and decreasing barriers to change; Andreasen, 2002; Janssen, Mathijssen, van Bon-Martens, Van Oers, \& Garretsen, 2013).

Five systematic reviews focused on the impact of social-marketing campaigns on drug consumption (cigarettes, alcohol, and illicit drugs). Review Quality B: Janssen et al. (2013, $k=6$ ) concluded that the impact of social-marketing campaigns could not be assessed due to lack of quality studies. Stead, Gordon, Angus, \& McDermott, (2007, $k=35)$ used a problematic votecounting approach (comparing the number of studies with significant vs. nonsignificant results) to conclude that social-marketing principles could be effective in reducing use of tobacco, alcohol, and illicit drugs. Review Quality C: Hung (2017, $k=48$ ) concluded interventions based on social-marketing principles had small significant effects on smoking, but no effect on alcohol consumption. Almestahiri, Rundle-Thiele, Parkinson, \& Arli, $(2017, k=8)$ concluded that social-marketing interventions can positively influence smoking behaviors (e.g., quit attempts and smoking prevalence). Kubacki, Rundle-Thiele, Pang, \& Buyucek, $(2015, k=10)$ found positive results in six of 10 studies and concluded that social marketing was largely effective in reducing alcohol consumption.

\subsection{Location bans}

This category included bans on cigarette smoking in public places. Typically, legislative bans and policies prohibit smoking in public spaces (e.g., restaurants and trains) and workplaces (e.g., offices, hospitals, schools, and universities).

Seven systematic reviews focused on the impact of location bans on cigarette consumption. Review Quality A: Frazer, McHugh, Callinan, \& Kelleher, $(2016, k=17$, NSRI) concluded that location-based smoking policies in hospitals, prisons, and universities can reduce smoking rates, although they noted that the evidence quality was low. Review Quality B: Monson and Arsenault (2017, $k$ $=16$, BA \& L) concluded legislated bans on smoking in public areas had an overall positive effect on reducing smoking rates at home. Frazer, Callinan, et al. (2016, $k$ $=77$, NSRIs) concluded that the impact of smoking bans on smoker numbers and cigarette consumption were inconsistent, but that national bans were effective. Review Quality C: Bennett, Deiner, \& Pokhrel, (2017, $k$ $=11$, NRSI, mostly cross-sectional) concluded that more longitudinal studies were needed, while noting two promising studies showing that smoke-free policies significantly reduced smoking at universities. Hopkins et al. (2010, $k=57, \mathrm{BA})$ concluded smoke-free policies reduce tobacco consumption, but their results were less compelling when only the strongest study designs were assessed. Bell et al. (2009, $k=16$, NRSI: one quasi experimental, three cohort, 12 cross-sectional) concluded that smoking bans at worksites can reduce overall cigarette consumption but results varied across sub-groups (e.g., less impact on low income groups) and bans may have unintended consequences (e.g., displacement of smoking). Chapman et al. (1999, $k=19$ ) found 18 of 19 studies showed smoke-free policies reduced daily smoking during working hours.

\section{6 | Norm appeals}

Social norms are rules or standards about how members of a community should behave. They range from the explicit (e.g., laws and regulations) to the implicit and unspoken (e.g., norms about where to sit on a train). A norm appeal communicates a desirable social norm with the aim of altering people's behavior towards that norm. A common example involves providing personalized normative feedback about actual consumption (e.g., average student drinking norms) so that outliers (e.g., students who drink more than average) adjust their behavior towards the norm (Wood, Brown, \& Maltby, 2012).

Three systematic reviews focused on the impact of social-norm appeals on alcohol consumption. Review Quality A: Prestwich et al. (Prestwich et al., 2016, $k=41$, RCT) concluded even large changes in beliefs about social norms produce only small changes in alcohol intake, and thus norm appeals should be combined with other interventions. Foxcroft, Moreira, Santimano, \& Smith, (2015, $k=66$, RCT) found social-norm appeals had small but significant effects on drinking frequency and quantity (namely, 0.9 alcoholic drinks less per week compared to a baseline of 13.7 drinks). However, they suggested the effect sizes may be too small to be practically useful. Dotson, Dunn, \& Bowers, (2015, $k=8$, 
13 RCT) concluded that personalized normative feedback had a small but clinically relevant impact on college student drinking (a reduction of $\approx 3$ drinks per week).

\section{7 | Risk warnings}

These interventions draw consumers' attention to the potential risks of consuming a harmful product. Most evidence on reducing harmful consumer demand assessed through systematic reviews has focused on the impacts of highlighting risks to personal health (e.g., requiring cigarette packages to display graphic images of smokingrelated diseases). The results therefore may not generalize to risk warnings outside this specific context (e.g., risks to reputation, conservation outcomes, or cruelty to animals).

Eight systematic reviews focused on the impact of risk-warning messaging on mostly tobacco, and to a lesser extent, alcohol consumption. Review Quality A: N. Clarke et al. (2021, $k=12$, RCT) concluded health warning labels have significant potential for decreasing the selection of unhealthy food and drink products. However, they noted all experimental studies to date had been conducted in the laboratory or online. Sheeran, Harris, \& Epton, (2014, $k=209$, RCT) concluded heightening risk appraisals (namely risk perceptions, anticipated emotions, and perceived severity) had a small but significant impact on smoking, but not on alcohol consumption. Risk warnings were most effective when accompanied by appeals to self-efficacy (confidence in one's ability to change towards a recommended behavior) and responseefficacy (perceptions about how much the recommended behavior will alleviate the hazard). Review Quality B: Noar, Hall, et al. (2016, $k=37$, RCT) concluded that pictorial warnings were more effective than text warnings for most nonbehavioral outcomes (e.g., elicited negative attitudes towards smoking). However, they identified only a single experimental study that assessed their impact on behavior. Tannenbaum et al. $(2015, k=127$, RCT) concluded fear appeals positively influenced behaviors in all but a few circumstances. Monárrez-Espino, Liu, Greiner, Bremberg, \& Galanti, $(2014, k=12,5$ RCT) concluded there was poor evidence for, or against, the sustained impact of pictorial health warnings on smoking. The authors noted that risk warnings are likely to have a modest impact on behavior. Peters, Ruiter, \& Kok, (2013, $k=13$, RCT) concluded that threatening communications were only effective when the target population had high self-efficacy. Review Quality C: Noar, Francis, et al. (2016, $k=22$ NRSI) concluded that strengthened cigarette-pack warnings (e.g., increased size of text warning, change from text to graphic image) reduced smoking and increased cessation. Scholes-Balog, Heerde, \& Hemphill, (2012, $k=10$, NRSI) concluded that alcohol warning labels were not associated with changes in self-reported risky alcohol use among adolescents.

\section{8 | Meta-analytic summary}

Figure 1 provides a visual summary of the primary effect size reported in each systematic review that included a meta-analysis (Supplementary Data Analysis). Effect sizes in Figure 1 are displayed to demonstrate whether each intervention type was effective in reducing a harmful consumer behavior, ineffective, or counterproductive (i.e., increased harmful consumer behavior). Social marketing, location bans, norm appeals, and risk warnings were all effective. The effectiveness of the latter two interventions was particularly robust and noteworthy across multiple meta-analyses of high-quality reviews (norm appeals) and moderate to high-quality reviews (risk warnings). By contrast, mass-media campaigns, incentives, and advertising bans generally had no effect on behavior. Reassuringly, none of the intervention types were counterproductive.

\section{3 | DISCUSSION}

Our analysis sought to provide a broad overview of the evidence, from outside the conservation literature, on seven types of interventions that aim to reduce harmful consumption. Some results will come as a surprise to many engaged in delivering demand-reduction campaigns for overexploited wildlife products. Notably, two of the most commonly used approaches to effecting behavior change for conservation-mass-media campaigns and incentive programs-were ineffective, on average. Moreover, any effects of incentive programs disappeared shortly after programs ended ( $>3$ months). In contrast, the two strategies that emerged as most supported, with some caveats, have been under-utilized (norm appeals; Kidd et al., 2019) or actively resisted by some in conservation (risk warnings; Kidd, Bekessy, \& Garrard, 2019b). We found some evidence the remaining three interventions can be effective, namely advertising bans, social marketing, and location bans, but a lack of robust evidence precluded firm conclusions about their overall impact.

We also found that none of the intervention types appear, on average, to be counterproductive. This finding must be interpreted with some caution as the reviewed literature contains only a few precisely estimated zero effects from well-designed studies, and instead contains 


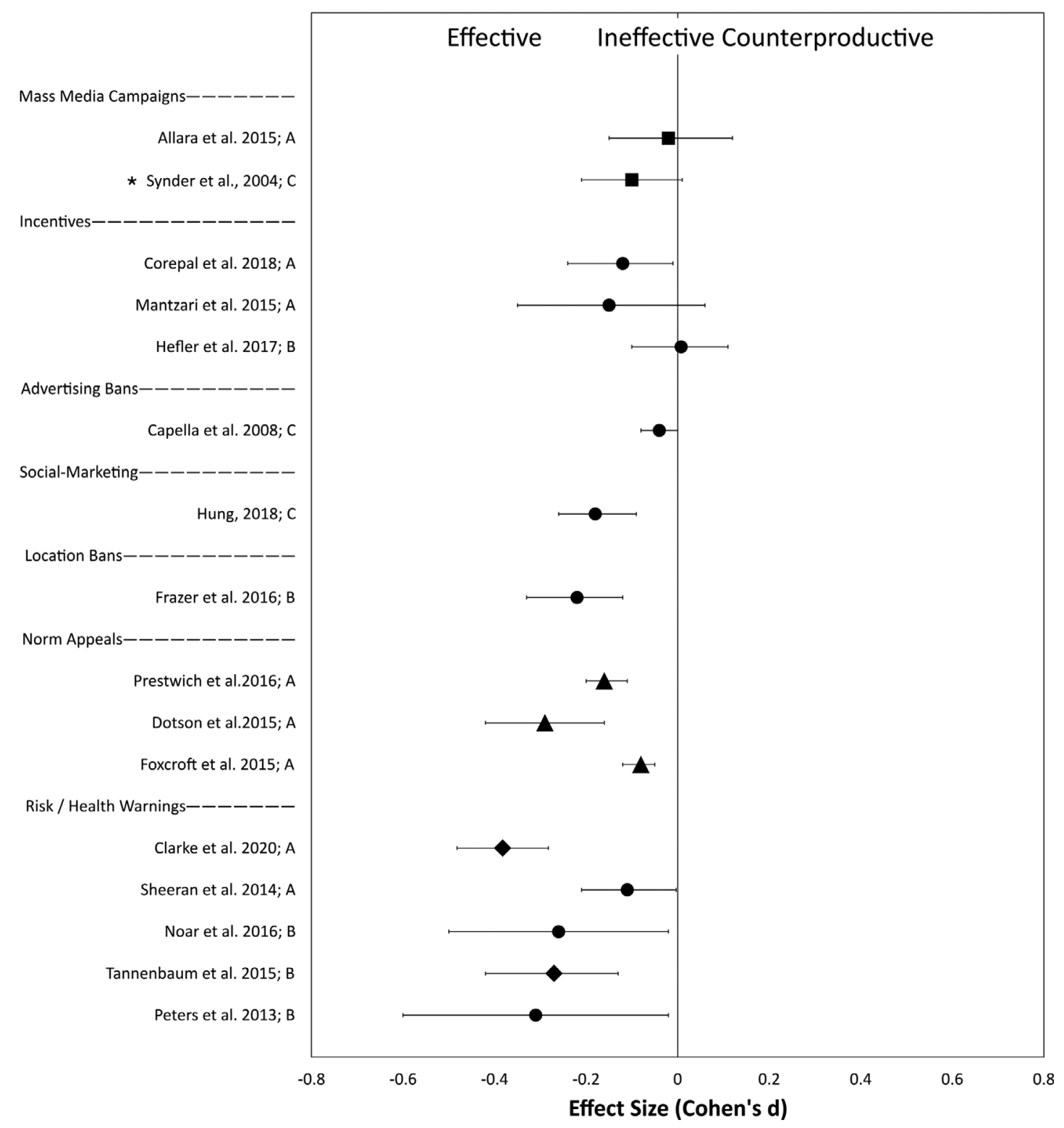

F I G U RE 1 Forest plot of effect sizes (Cohen's $d$ ) for each systematic review containing meta-analysis (error bars represent 95\% confidence intervals). Effect sizes indicate whether an intervention was effective (cases where the upper confidence interval sits below zero), ineffective (cases where the confidence interval encompasses zero), or counterproductive (cases where the lower confidence interval exceeds zero) in reducing harmful consumer behavior. For transparency, we also include an assessment of each source's review quality (i.e., A, B, or C). *Snyder et al. (2008) did not provide confidence intervals. Thus, these were conservatively estimated based on the reported lack of significance. Symbol key: Squares = illicit drugs, circles $=$ tobacco, triangles $=$ alcohol, and diamond $=$ tobacco, alcohol, and other behaviors combined

many noisy estimates from poorly designed studies. However, the available data suggests there may be little risk in investigating whether combinations of multiple approaches are more effective than individual approaches. Indeed, there is already considerable overlap between our broadly defined intervention types, such as location bans that signal social norms or social-marketing campaigns that utilize mass-media. However, the nonmutually exclusive nature of our taxonomic categories is also problematic in that they may be difficult to tease apart, which makes replication and drawing firm conclusions potentially difficult. The inability to completely distinguish between intervention types suggests future research might benefit from exploring alternative frameworks for assessing campaign efficacy, such as costbenefit analysis or compatibility with theoretical behavior-change frameworks (e.g., Michie, Van Stralen, \& West, 2011).

Interestingly, despite the considerable investment in evaluating behavior-change campaigns within the public 
health domain, many systematic reviews were unable to draw firm conclusions about the impact of several popular approaches, owing to a lack of robust study designs. Specifically, systematic reviews of mass-media campaigns and social marketing often concluded that multiple methodological shortcomings limited conclusions, whereas higher quality reviews concluded that insufficient high-quality studies prevented firm conclusions being reached. This highlights the importance of considering evidence quality when drawing conclusions about the impact of a particular intervention.

We now discuss results of each specific intervention type with reference to insights from psychology and consider to what extent, and under what contexts, each might be useful in reducing demand for wildlife products.

\subsection{Interventions found to be generally ineffective}

\subsection{1 | Mass-media campaigns}

Mass-media campaigns are often seen as synonymous with awareness raising, arguably the most common behavior-change approach in conservation (Kidd, Garrard, et al., 2019). Despite their popularity, massmedia campaigns were adjudged to be ineffective in all four meta-analyses. Only one of nine systematic reviews, with multiple methodological limitations, suggested there was strong evidence supporting the use of mass-media campaigns. This review noted that effectiveness varied with message content, with strongest evidence for messages highlighting health risks. The remaining eight reviews argued that the low quality of primary evidence precluded firm conclusions about effectiveness

These results do not mean that all reviewed mass-media campaigns were ineffective. Systematic reviews of massmedia campaigns tended to encompass other interventions, which were more targeted and supported by insights from psychology, and that were found to be effective when considered separately, such as norm appeals and risk warnings. We thus restrict our critique of mass-media campaigns to those that fail to target specific psychological drivers of harmful consumption other than lack of awareness.

A major problem with awareness-raising campaigns is they rely on an intuitive, but incomplete, mental model of human behavior- "if people only knew what I know about this problem, then they would change their behavior." This is the information-deficit model-the assumption people's behavior will change once they have the right information (Sturgis \& Allum, 2004). However, much research shows that access to information is only one of many competing influences on human behavior
(MacFarlane, Hurlstone, \& Ecker, 2020; Marteau, Hollands, \& Fletcher, 2012; Rossen, Hurlstone, \& Lawrence, 2016). For example, the success of a campaign to increase household recycling will be limited by structural barriers such as access to recycling facilities, cost of services, and inconvenience to householders. Even when such barriers are low, the success of an intervention may be limited by internal psychological barriers such as lack of motivation to participate in recycling programs or a widespread perception that it is socially acceptable not to recycle (Hornik, Cherian, Madansky, \& Narayana, 1995).

We advise conservation practitioners against using mass-media campaigns that ignore the structural or psychological barriers to behavior change (Figure 2). This conclusion is shared by those who have argued that organizations seeking social change should not solely rely on awareness-raising (Burgess, 2016; Christiano \& Neimand, 2017).

\subsection{2 | Incentives}

All three systematic reviews of incentives noted their analyses were based on a small number of studies so results should be interpreted with caution. Nevertheless, two concluded that incentives were probably ineffective and the third found they can be effective, but only in the short-term.

Incentive schemes for reducing environmental harms are likely familiar to many conservationists (Pearce \& Turner, 1990), including those combating the supply side of the illegal wildlife trade (Bulte, van Kooten, \& Swanson, 2003). However, to the best of our knowledge, such schemes have not yet been applied to the demand side (i.e., to discourage consumption).

On the available evidence, we caution against using incentives to target long-term behavior in wildlife consumers. Practitioners who use incentives should be prepared to robustly test their effectiveness. The reasons incentive schemes can fail to change behavior include: (i) introducing extrinsic incentives can undermine people's intrinsic motives, thereby reducing overall motivation to conserve wildlife (Rode, Gómez-Baggethun, \& Krause, 2015); (ii) incentives can lead to "moral licensing" that enables people to "pay" some financial cost to offset any feelings of guilt, and thus encourages even more problematic behaviors (e.g., to buy more wildlife products; Bowles, 2009); and (iii) incentives tend to have short-term effects, meaning once the incentive is withdrawn, people revert to their previous behaviors (P. Schultz \& Kaiser, 2012). An alternative approach to incentives may be to invigorate and amplify existing consumer intrinsic motivations towards conserving wildlife 


\section{Interventions}

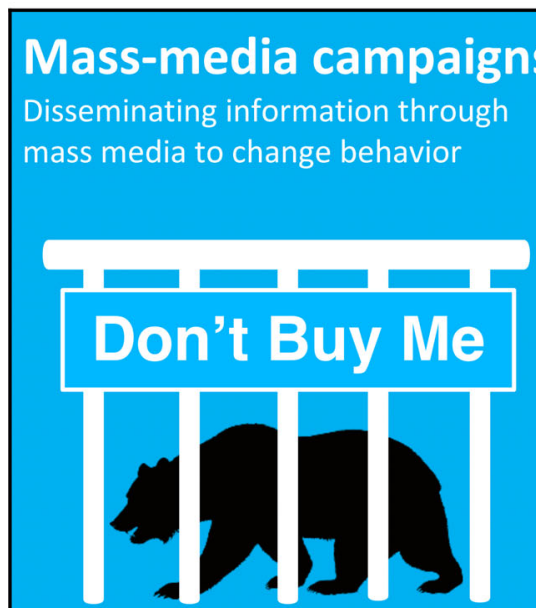

Aims to raise awareness

e.g., billboard ads highlighting the

cruelty of wildlife products

\section{Incentives}

Promising benefits or losses changes

consumer behavior

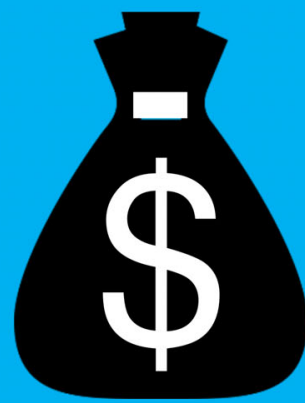

Aims to encourage commitment Includes contests, competitions, incentive schemes, lotteries etc.
Problem

\section{Generally ineffective}

Awareness is often insufficient to change behavior

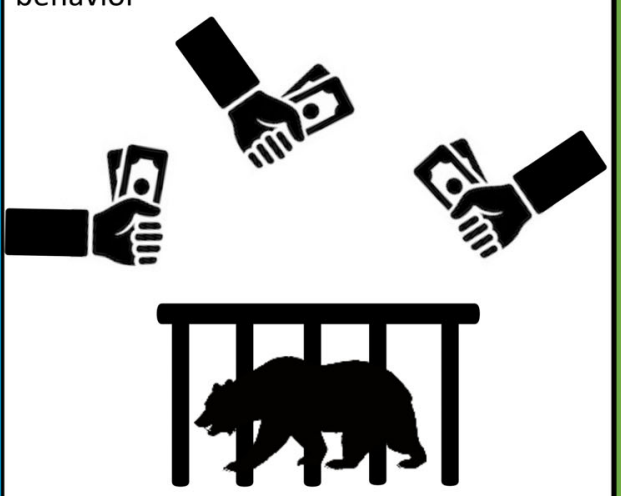

Ignores barriers

Success is often limited by structural

(e.g., costs) and internal (e.g., normative perceptions) barriers

\section{Short-lived or ineffective}

Benefits tend to disappear shortly after incentives end and can undermine people's intrinsic motives and facilitate moral licencing
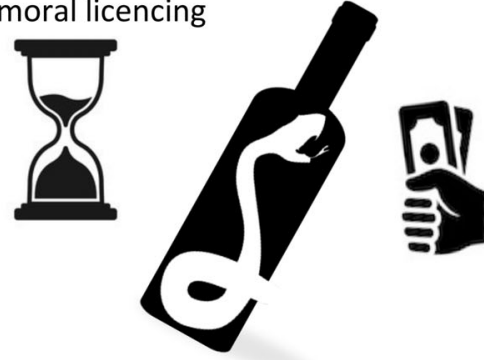

Moral licensing

Financially punishing people can backfire, enabling them to "pay" to offset the guilt and further engage in consumption

\section{Solution}

\section{Evidence not intuition}

Target the specific structural and psychological barriers to change

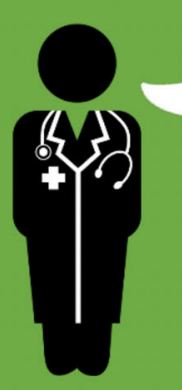

Debunk existing misperceptions

e.g., by communicating how the

scientific evidence shows that bear bile is not an effective remedy

\section{Apply caution}

There may be a role for incentives, but robust evaluation and caution is needed

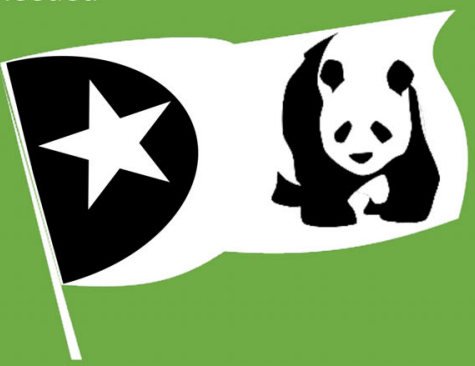

Instead, use intrinsic motivations

Highlight people's intrinsic

motivations (e.g., national pride) in protecting wildlife

F I G U RE 2 Summary of interventions found to be, on average, ineffective

(Figure 2), such as by making flagship species a symbol of national pride (Smith, Salazar, Starinchak, ThomasWalters, \& Veríssimo, 2020).

\section{2 | Promising interventions that require more robust evidence}

\subsection{1 | Advertising bans}

There is limited evidence that advertising bans can be effective in reducing harmful consumer demand. Five of six reviews noted there was insufficient evidence to draw strong conclusions, yet half nonetheless still concluded that they can be effective. In support, McNeill et al. (2017) noted that studies have consistently shown consumers prefer branded over plain-packaged cigarettes. In the reviews classed as having two or more limitations, two concluded that the evidence generally supported the use of advertising bans, whereas one concluded advertising bans did not reduce cigarette consumption.

Given the limited evidence, we recommend that wildlife researchers first evaluate whether, and to what extent, advertising drives consumer demand for wildlife products (Figure 3). For example, practitioners could conduct a randomized controlled experiment assessing 
consumers' hypothetical willingness-to-pay (MacFarlane, Hurlstone, \& Ecker, 2021) for plain-packaged vs. branded wildlife products (see Figure 4 for examples). If branding is shown to significantly increase wildlife consumer demand, then practitioners should consider how to limit advertising/branding of wildlife products (e.g., by

\begin{tabular}{|c|c|c|}
\hline Interventions & Problem & Solution \\
\hline $\begin{array}{l}\text { Advertising bans } \\
\text { Bans or restrictions on advertising } \\
\text { that promotes the consumption of } \\
\text { harmful products }\end{array}$ & $\begin{array}{l}\text { Insufficient evidence } \\
\text { There is insufficient evidence to draw } \\
\text { strong conclusions about advertising bans } \\
\qquad \text { Evidence }\end{array}$ & $\begin{array}{l}\text { Evaluate the impact } \\
\text { of advertising \& branding } \\
\text { compared to other motivators (e.g., } \\
\text { health concerns, social norms, } \\
\text { culture, hedonism etc.) } \\
\qquad \begin{array}{l}\text { Control Branding } \\
\text { group I }\end{array}\end{array}$ \\
\hline $\begin{array}{l}\text { Design principles } \\
\text { Include consumer segmentation (e.g., } \\
\text { focus on businessmen) \& exchange } \\
\text { (e.g., highlight benefits \& remove } \\
\text { barriers to change) }\end{array}$ & $\begin{array}{l}\text { Lacks consistency } \& \text { evidence } \\
\text { Social marketing is often poorly defined, } \\
\text { inconsistently applied, and inadequately } \\
\text { tested } \\
\qquad \text { Evidence }\end{array}$ & 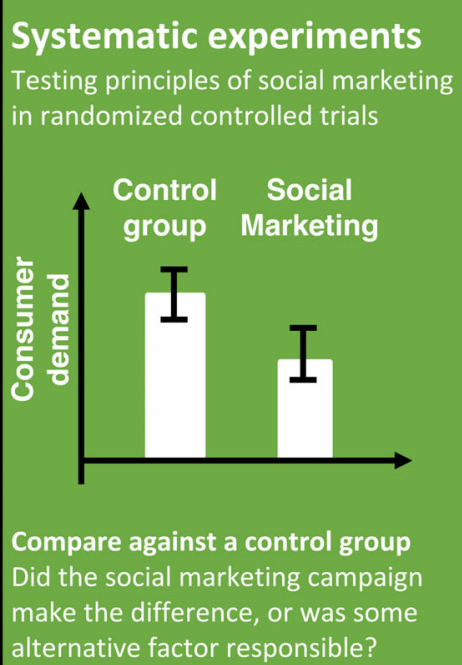 \\
\hline $\begin{array}{l}\text { Locations bans } \\
\text { Aim to prohibit harmful consumption } \\
\text { at certain locations, such as } \\
\text { restaurants and workplaces }\end{array}$ & $\begin{array}{l}\text { Evidence limited to smoking } \\
\text { The impact of location bans may not be } \\
\text { generalisable to behaviours other than } \\
\text { smoking }\end{array}$ & $\begin{array}{l}\text { Carefully evaluate } \\
\text { Evaluations should consider whether } \\
\text { prohibitions have reduced demand } \\
\text { overall, or mostly displaced it }\end{array}$ \\
\hline $\begin{array}{l}\text { Reduces consumption many ways } \\
\text { Directly (e.g., banned at official } \\
\text { banquets) \& indirectly (i.e., signals } \\
\text { that consumption is socially } \\
\text { unacceptable \& less common) }\end{array}$ & $\begin{array}{l}\text { Might displace consumption } \\
\text { While one review suggested location bans } \\
\text { could simply displace consumption to } \\
\text { private areas, the best evidence suggests } \\
\text { this is unlikely. }\end{array}$ & $\begin{array}{l}\text { Consider lobbying for location bans } \\
\text { High profile bans (such as the ban on } \\
\text { shark fin soup on commercial flights } \\
\text { and prominent restaurants) likely } \\
\text { help to reduce consumer demand }\end{array}$ \\
\hline
\end{tabular}

F I G URE 3 Summary of interventions that are promising but more robust evidence is needed 
lobbying governments to penalize companies that produce product packaging).

If advertising motivates demand, then the effectiveness of bans will be limited by two factors. First, the illegal nature of much wildlife trade would make it difficult to enforce regulations. Second, effectiveness would be limited by how much influence advertising has on consumer demand compared to other factors such as health, hedonism, and culture (Thomas-Walters et al., 2021), and price, portability, and availability (Kurland, Pires, McFann, \& Moreto, 2017).

\subsection{2 | Social marketing}

Despite conservationists' growing enthusiasm for social marketing (Greenfield \& Veríssimo, 2019; MacMillan \& Challender, 2014; Wright et al., 2015) only a handful of campaigns have attempted to reduce demand for wildlife products (Veríssimo \& Wan, 2019). Outside conservation, there was poor-quality evidence to support this approach. Of two reviews, each classed as having a single methodological limitation, one found insufficient evidence to draw conclusions while the other suggested the approach could be effective but acknowledged many studies found no benefit. Conclusions were mixed in the three remaining reviews, each with multiple methodological limitations.

Two limitations must be considered. First, social marketing has often been used inconsistently, and opportunistically (Janssen et al., 2013), with many studies misconstruing social marketing as simply advertising or communication for social goals (Greenfield \& Veríssimo, 2019; Stead et al., 2007). Thus, systematic reviews cannot simply rely on assessing interventions labeled as "social marketing" because not all incorporate key social-marketing principles. Second, one core principle of social marketing is the use of multiple

(a)

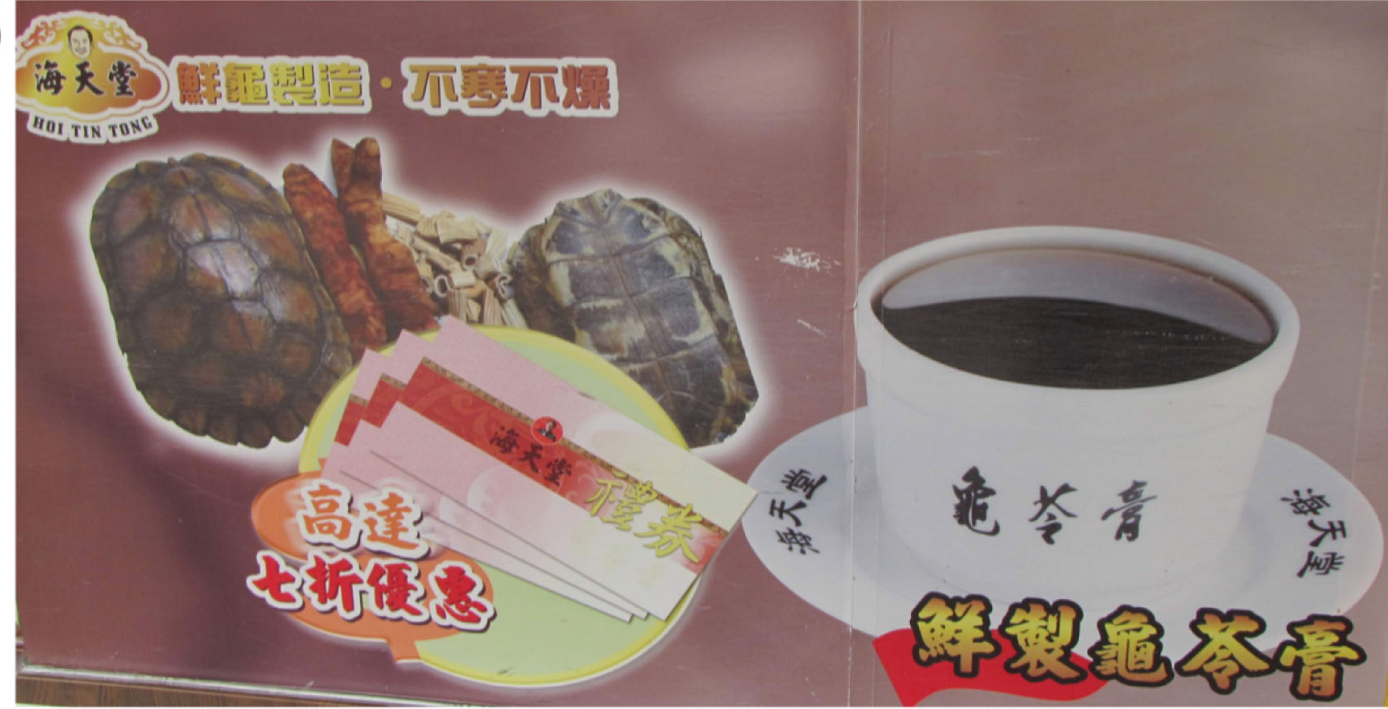

(b)

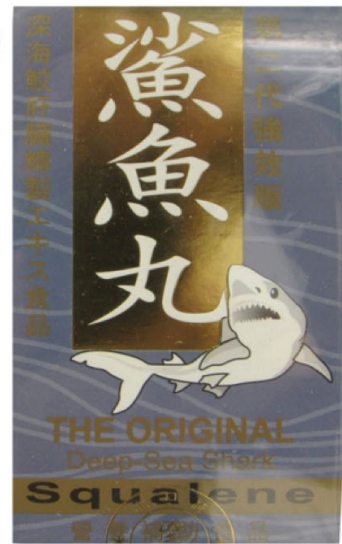

(c)

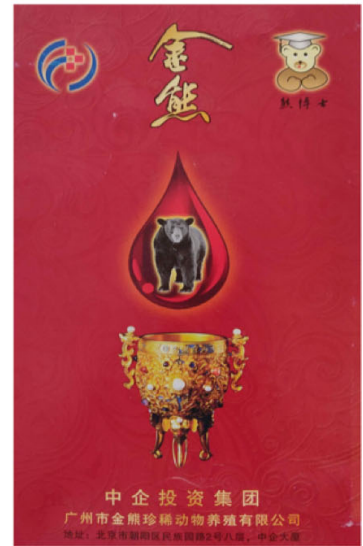

(d)

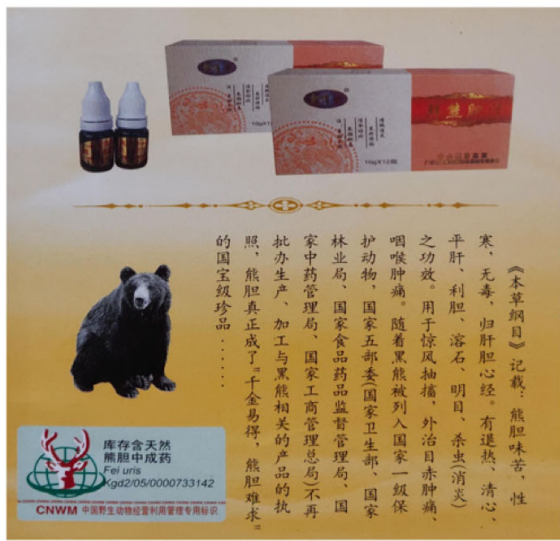

F I G U R E 4 Example branding for wildlife products. (a) Herbal "turtle jelly" (Gui-Ling-Gao, contains turtle plastron), photo by Diogo Veríssimo; (b) shark liver oil capsules, photo by Diogo Veríssimo; (c) and (d) bear bile extract, photos by Amy Hinsley 
interventions, which can range from TV commercials to education campaigns. In practice, this renders it difficult to determine which strategies have been effective. Hung (2017) also noted that most studies of socialmarketing campaigns did not provide adequate information about study designs or methods.

Despite these limitations, several social marketing principles (Janssen et al., 2013) are valuable in guiding design of effective behavioral interventions. One is exchange: to increase the uptake of a desired behavior, interventions should increase consumer motivations to adopt the behavior, and remove barriers to doing so. Another useful principle is segmentation: dividing larger heterogeneous groups of people into smaller more homogenous groups who may share important values, motives, behaviors, attitudes, and social pressures.

In conclusion, whilst the evidence for the effectiveness of social marketing in reducing the use of harmful products is weak, its principles may have merit (Firestone, Rowe, Modi, \& Sievers, 2017; Green, Crawford, Williamson, \& DeWan, 2019). We therefore advise practitioners considering using social marketing to influence wildlife consumers to employ robust experimental designs to evaluate the impact of interventions (Figure 3) that comply with core social-marketing benchmarks (Andreasen, 2002). Indeed, one recent robust evaluation of a social-marketing campaign found it successfully reduced unsustainable wildmeat consumption by $\approx 62 \%$ (Chaves et al., 2018; see also Salazar et al., 2019).

\subsection{3 | Location bans}

There was some evidence that banning harmful consumption in specific locations reduced cigarette consumption, including outside the banned locations. However, the latest and most comprehensive review (Frazer, McHugh, et al., 2016) noted overall evidence quality was low.

In addition to directly reducing consumption, location bans may operate indirectly by descriptive-norm appeals (i.e., making smoking less visible and hence signaling it is uncommon) and injunctive-norm appeals (i.e., signaling smoking is socially disapproved). Although one review noted location bans could displace consumption to private areas (Bell et al., 2009), more recent and comprehensive reviews did not support displacement (Frazer, McHugh, et al., 2016; Monson \& Arsenault, 2017). This highlights the importance of carefully evaluating these interventions to ensure that they reduce, rather than simply displace, demand (Figure 4).

Unfortunately, evidence in favor of location bans is limited to smoking. This provides limited evidence that similar impacts might be expected on eating or purchasing wildlife products in public places (e.g., marketplaces, restaurants, or governmental banquets). Nevertheless, the results suggest that bans on conspicuous wildlife consumption may be a potent way to reduce overall demand for wildlife products (Chaves et al., 2018; Truong, Dang, \& Hall, 2016). Indeed, the apparent reduction in demand for shark-fin soup in mainland China (Vallianos, Sherry, Hoford, \& Baker, 2018) might be linked to bans on consumption in prominent locations (e.g., hotels, restaurants, and airline menus; Whitcraft et al., 2014). Arguably the most significant location ban was in 2013 when Chinese authorities banned the consumption of shark-fin soup, bird nests, and other wild animal products at official banquets ( $\mathrm{Ng}, 2013)$.

\subsection{Interventions found to be generally effective}

\subsection{1 | Norm appeals}

There was consistent evidence in all three reviews without any methodological limitations that norm appeals can have a small impact on consumer demand for alcohol. Two reviews noted that these effects were clinically relevant but the third suggested they were too small to be useful for policy. Importantly, one review, Dotson et al. (2015), focused only on personalized normative feedback-individualized feedback on a person's drinking behavior-whereas the other two reviews also assessed generalized social norms. The focus on individualized norms may have explained Dotson et al.'s relatively stronger support for the impact of social norms.

Three key findings from our analysis may help ensure conservationists have realistic expectations about the potentially limited impact of norm appeals. First, while social influences and normative beliefs can be changed by, for example, communicating how much others drink, these belief changes produce only small changes in consumption. Consequently, norm appeals are likely to be more effective when accompanied by other interventions. Second, impersonal social norms may be less effective than personalized normative feedback. However, such highly targeted approaches will not be feasible for many, often hidden, wildlife consumption behaviors. Third, poorly designed norm appeals can backfire if they inadvertently suggest that many people are engaged in the undesired social conduct (Schultz, Nolan, Cialdini, Goldstein, \& Griskevicius, 2018).

In designing norm appeals to reduce demand for wildlife products, we recommend that practitioners pilottest norm appeal messages (Figure 5) to ensure that they are targeted, persuasive, and do not backfire (Burgess, 2016; Cialdini, 2003), before using them in 
campaigns. We also advise practitioners to refer to one of the many science-based guides for designing effective norm appeals (Farrow, Grolleau, \& Ibanez, 2017; MacFarlane et al., 2020; Rare \& Team, 2019). They should also augment such appeals with other promising interventions, such as risk warnings.

\subsection{2 | Risk warnings}

Of the seven intervention types reviewed, evidence was strongest on the impact of warnings about risks to individual's health. Six of seven reviews concluded that risk warnings were effective in reducing cigarette or alcohol consumption, with an eighth concluding they are effective in altering unhealthy food selection. Only one review, with multiple methodological limitations, concluded that risk warnings do not reduce self-reported risky alcohol consumption in adolescents. Risk warnings that were effective typically included messages to boost self-efficacy (people's ability to adopt the recommended behavior) and response-efficacy (people's perception about how changing their behavior will alleviate the risks). They incorporated pictorial health warnings

\section{Interventions}

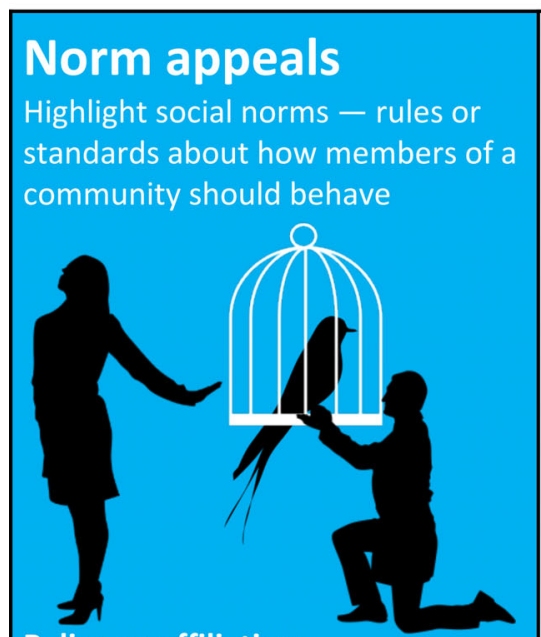

Relies on affiliations

Examples range from explicit (e.g.,

laws and regulations) to implicit

(e.g., where to sit on a train) norms

\section{Risk warnings}

Draw attention to the potential

risks of consumption (e.g., to health

or reputation)

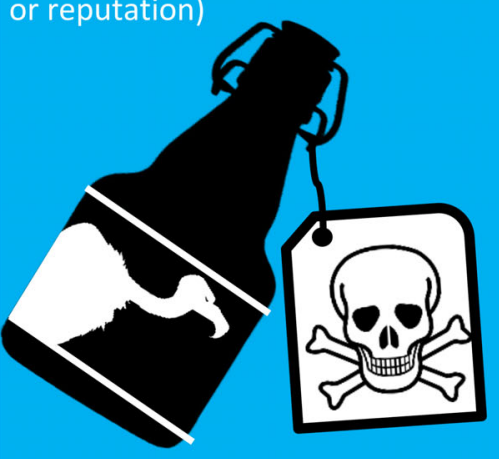

Aims to inform \& dissuade

Examples include graphic images of

diseases that could result from

consuming a product
Problem

\section{Small impacts}

Even large changes in normative beliefs tend to engender only small changes in consumption

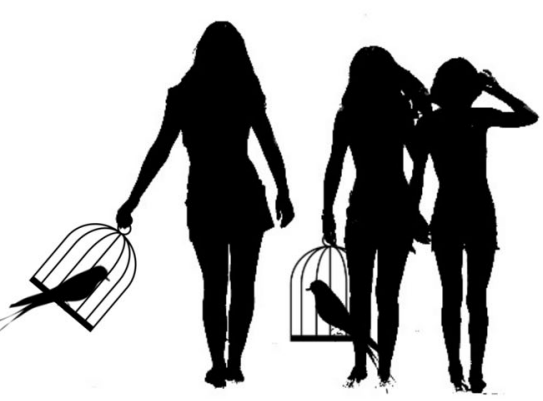

Can also backfire

Poorly designed campaigns can implicitly highlight undesirable norms and encourage conformity in wrong direction

\section{Self-efficacy is essential}

People must have capacity to change behavior, and believe the change will mean they avoid the risk

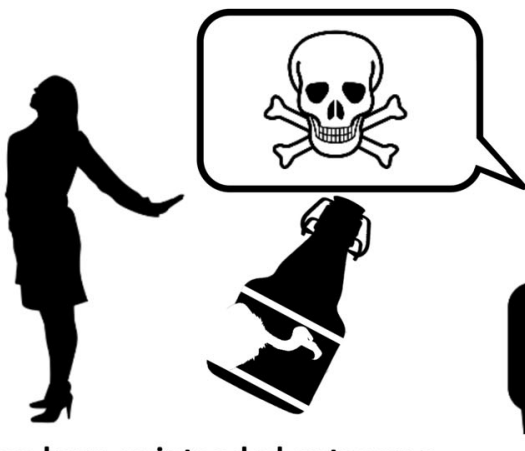

\section{Can have unintended outcomes}

For example, could contribute to the misguided anger towards wildlife (i.e., not just a fear of the the products)

\section{Solution}

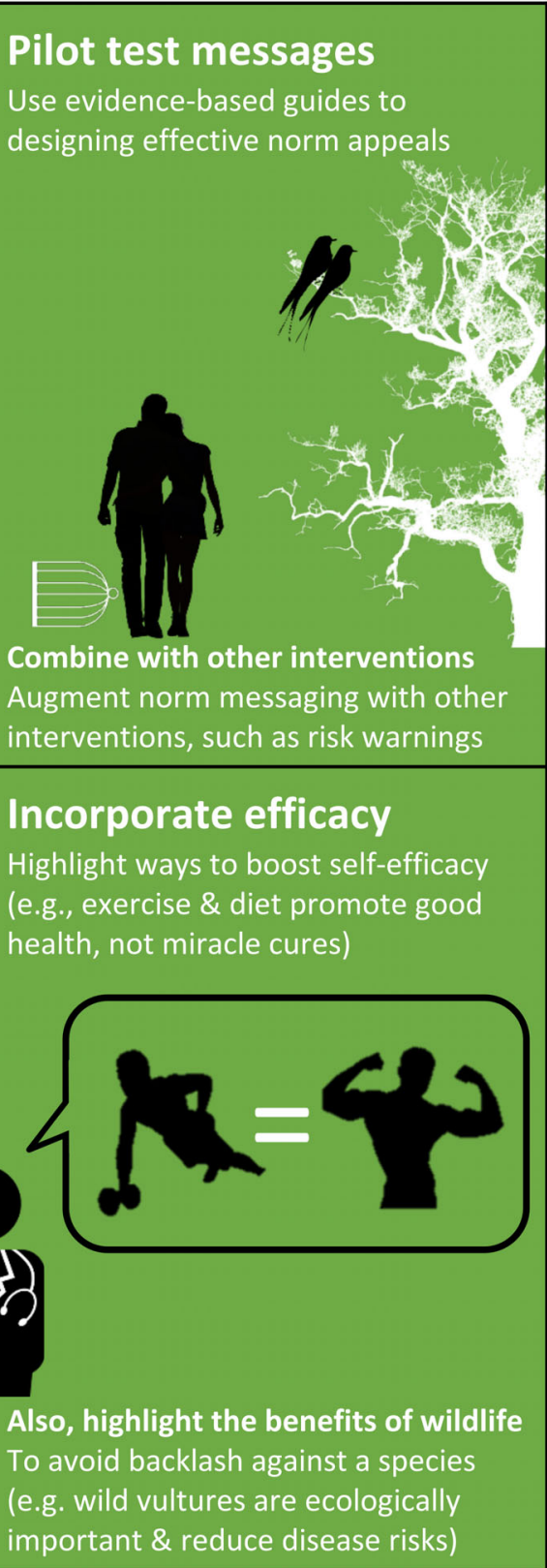

F I G URE 5 Summary of interventions found to be effective, with important caveats 
(vs. text only), and emphasized high susceptibility (i.e., the vulnerability of the target group; Tannenbaum et al., 2015)

Our findings were confined to health-related warnings and so may not generalize to warnings about other risks relevant to conservation contexts (e.g., risks to reputation, conservation outcomes, or cruelty to animals). We also acknowledge that health-risk warnings are likely to be met with resistance from some conservationists. Despite the pervasive use of risk messaging in political, advertising, and public-health campaigns, conservationists have fiercely debated whether optimistic or pessimistic communication framing strategies are better at inducing behavior change (Kidd, Bekessy, \& Garrard, 2019b). Yet, Kidd, Bekessy, and Garrard (2019b) noted that the papers advocating for either approach substantially outnumber the papers providing empirical, conservation-specific evidence. They called for building a stronger evidence base on the best ways to communicate conservation messages.

The present review does not aim to settle the debate because the target behaviors of many conservation communications were outside the present focus (e.g., donation, policy support, environmental action). However, our synthesis indicates that warning people about the health risks of their behaviors can reduce demand. As many activities within the wildlife trade carry significant health risks-such as heightened risk of zoonoses from bushmeat consumption (Alexander et al., 2015), animal markets (Johnson et al., 2015), and hunting (Johnson et al., 2020)—conservationists should consider using risk warnings to reduce consumer demand for overexploited wildlife products. Indeed, in light of the devastation caused by the COVID-19 coronavirus pandemic, conservationists may have a moral responsibility to incorporate factual health-risk warnings into communications about wildlife trade activities (for conservation relevant guidance, see MacFarlane \& Rocha, 2020).

In our view, rather than asking whether negative or positive messages are more effective, we agree with McAfee and Connell (2019) that greater appreciation is needed for how the two framing approaches can work independently and in tandem, and how their effectiveness may vary with context. Experiments show people's evaluations of risks and benefits tend to be negatively correlated (Alhakami \& Slovic, 1994). For example, if antibiotics are portrayed as effective, this will encourage the perception they are also low in side effects, and vice versa. Equally, if pesticide use is considered high risk, this will encourage the perception it is less effective, and vice versa. Thus, by communicating that consuming primate meat is both high in risk (e.g., of contracting disease; Peeters et al., 2002) and low in benefit (no more nutritious than other forms of protein), both elements can be used to reduce people's perception of the value of the product. Indeed, a recent experiment found that while the perceived value of an ineffective health remedy could be reduced by communicating either its lack of benefits (by 23\%) or its potential health risks (by 30\%), communicating both produced the largest reduction in perceived value (by 50\%; MacFarlane et al., 2021). These results have implications for framing conservation messaging about traditional health remedies that contain wildlife products.

Careless risk messaging can also have negative conservation outcomes. For example, recent communications about the health risks posed by consuming bats (e.g., the potential for contracting novel zoonoses) may have reduced conservation support and increased violent retaliation towards wild bat communities (Zhao, 2020). One way to neutralize the unintended effects of risk communications is to highlight ways to boost self-efficacy (Figure 5), and include messages about potential benefits of wildlife conservation (e.g., the positive ecological impacts of wild bats; $\mathrm{Lu}$ et al., 2017). Another tactic is to put the risk into context, for example, by communicating the risks of zoonoses from a diverse range of animals. This may discourage contact with animals, while avoiding disproportionate negative attention to individual species (Davis, Goldwater, Ireland, Gaylord, \& Van Allen, 2017). For further guidance on risk communications, see MacFarlane and Rocha (2020).

\section{4 | Potential limitations}

There are several potential limitations of our review. First, we need research to assess whether the insights gleaned from our analysis will generalize to addressing the wildlife trade. Therefore, conservationists should apply one or more of the intervention types reviewed with caution and use robust experimental intervention designs to ensure that subsequent evaluations can improve the evidence base.

Second, in presenting such a broad overview of the literature we have necessarily oversimplified many of the cultural and contextual differences between the consumption of specific harmful products (e.g., alcohol and cigarettes) and many wildlife products. For instance, the evidence reviewed mostly originates from countries that are Western, educated, industrialized, rich, and democratic, with populations that may have distinct cognitive and motivational differences from non-Western countries (Henrich, Heine, \& Norenzayan, 2010). While this may limit generalizability to non-Western countries, we 
nevertheless hope our approach provides valuable insights on how to modify consumer behavior.

Third, while we adopted a systematic approach to assessing literature, three elements of gold standard systematic review methods were not included. These included (i) pre-registering a review protocol; (ii) recruiting multiple researchers to apply the exclusion criteria and conduct data extraction in duplicate (thus also precluding consistency checking at these stages); and (iii) preserving the originally proposed exclusion criteria, since additional criteria had to be added (i.e., the scope of the relevant intervention types extended to include financial incentives, education projects, and brief interventions) after the initial screening phase to ensure the final list of papers was sufficiently applicable to the project. These omissions reflected both available resources and the primary purpose of the review being to identify promising intervention foci rather than necessarily exhaustively collate the existing literature.

Fourth, by excluding nonsystematic reviews, we may have missed some primary literature. This limitation is somewhat offset by the fact the included systematic reviews have already collated, screened, and applied quality-control processes to much of the relevant literature and undergone peer review.

Fifth, we neglected to include a systematic review filter (e.g., explicit search terms for "meta-analyses," "quantitative synthesis," "metaregression," and other related terms), meaning that some relevant reviews may have been excluded from our search. However, we are hopeful that the included search terms were sufficiently broad so as to capture the majority of reviews.

Finally, our categorization of evidence into broad intervention types invariably oversimplifies the details of successful intervention campaigns. We acknowledge, for example, not all location-based campaigns are identical.

\section{4 | CONCLUSION}

Conservationists have sought to reduce consumer demand for overexploited wildlife products to address the current biodiversity crisis. Many are now calling for reductions in the wildlife trade to reduce the risk of pandemics. We sought to learn from systematic reviews of interventions that aim to reduce consumer demand for harmful products such as alcohol and tobacco. We found that mass-media campaigns were, on average, ineffective and incentives were either ineffective or their effects were short-lived. Advertising bans, social marketing, and location bans are promising approaches but more highquality evidence is needed to draw firm conclusions. There was more robust evidence that norm appeals can be effective, but effect sizes were often too small to be useful for policy. We found robust evidence that risk warnings can be effective provided that key ingredients (e.g., message components for boosting self- and response-efficacy) are included. By learning from disciplines other than conservation, we can benefit from a vast body of scientific knowledge on "what works" to alter consumer behavior. Our findings thus provide some insights into why some conservation campaigns may be more effective than others. However, they also serve as a reminder that the conservation community has got to do more than simply evaluate whether the evidence provided by a set of studies is credible. It has to start generating its own credible evidence. Every conservation action that is done in a way that makes it difficult to ascertain its impact, and whether the underlying behavioral model is a good approximation of reality, is a missed opportunity for learning. We cannot just keep lamenting the poor state of the conservation evidence base. We have to do something about it.

\section{ACKNOWLEDGMENTS}

This research was facilitated by an Australian Government Endeavor Postgraduate Scholarship awarded to the first author. The authors would also like to thank Alec Christie, Phil Martin, and Silviu Petrovan for assisting with quality assessments and $\kappa$ analysis.

\section{CONFLICT OF INTEREST}

The authors declare no conflict of interest.

\section{AUTHOR CONTRIBUTIONS}

Douglas MacFarlane and William J. Sutherland led the conceptualization of the research. Douglas MacFarlane performed the systematic review, led the discussion among co-authors, and wrote the article. Mark J. Hurlstone revised the initial draft of the article with input from Douglas MacFarlane, Ullrich K. H. Ecker, Diogo Veríssimo, Wayne Hall, and William J. Sutherland. All authors contributed to conceptual development, provided search terms for the systematic review, discussed and contributed ideas, reviewed and vetted definitions and presentations of material, and collaborated in reviewing different drafts of the article.

\section{ETHICS STATEMENT}

The authors are not aware of any ethical issues regarding this study.

\section{DATA AVAILABILITY STATEMENT}

All data are presented in the article or the supplemental materials. 


\section{ORCID}

Mark J. Hurlstone (D) https://orcid.org/0000-0001-99206284

Sander van der Linden (1D https://orcid.org/0000-0002-

0269-1744

Diogo Veríssimo (1) https://orcid.org/0000-0002-3519-6782

William J. Sutherland (10 https://orcid.org/0000-0002-

6498-0437

\section{REFERENCES}

Alexander, K. A., Sanderson, C. E., Marathe, M., Lewis, B. L., Rivers, C. M., Shaman, J., et al. (2015). What factors might have led to the emergence of Ebola in West Africa? PLoS Neglected Tropical Diseases, 9(6), e0003652.

Alhakami, A. S., \& Slovic, P. (1994). A psychological study of the inverse relationship between perceived risk and perceived benefit. Risk Analysis, 14(6), 1085-1096.

Allara, E., Ferri, M., Bo, A., Gasparrini, A., \& Faggiano, F. (2015). Are mass-media campaigns effective in preventing drug use?: A cochrane systematic review and meta-analysis. BMJ Open, 5(9), $1-10$.

Allen, J. A., Duke, J. C., Davis, K. C., Kim, A. E., Nonnemaker, J. M., \& Farrelly, M. C. (2015). Using mass media campaigns to reduce youth tobacco use: A review. American Journal of Health Promotion, 30(2), e71-e82.

Almestahiri, R., Rundle-Thiele, S., Parkinson, J., \& Arli, D. (2017). The use of the major components of social marketing: A systematic review of tobacco cessation programs. Social Marketing Quarterly, 23(3), 232-248.

Andreasen, A. R. (2002). Marketing social marketing in the social change marketplace. Journal of Public Policy \& Marketing, 21(1), 3-13.

Anti, P., Owusu, M., Agbenyega, O., Annan, A., Badu, E. K., Nkrumah, E. E., ... Drosten, C. (2015). Human-bat interactions in rural West Africa. Emerging Infectious Diseases, 21(8), 1418-1421.

Bala, M. M., Strzeszynski, L., \& Topor-Madry, R. (2017). Mass media interventions for smoking cessation in adults. Cochrane Database of Systematic Reviews, 2017, CD004704.

Bayliss, H. R., Haddaway, N. R., Eales, J., Frampton, G. K., \& James, K. L. (2016). Updating and amending systematic reviews and systematic maps in environmental management. Environmental Evidence, 5(1), 1-7.

Bell, K., McCullough, L., Devries, K., Jategaonkar, N., Greaves, L., \& Richardson, L. (2009). Location restrictions on smoking: Assessing their differential impacts and consequences in the workplace. Canadian Journal of Public Health, 100(1), $46-50$.

Bennett, B. L., Deiner, M., \& Pokhrel, P. (2017). College antismoking policies and student smoking behavior: A review of the literature. Tobacco Induced Diseases, 15(1), 1-11.

Bowles, S. (2009). When economic incentives backfire. Harvard Business Review, 87(3), 22-23.

Brierley, A. S. (2007). Fisheries ecology: Hunger for shark fin soup drives clam chowder off the menu. Current Biology, 17(14), R555-R557.

Bulte, E. H., van Kooten, G. C., \& Swanson, T. (2003). Economic incentives and wildlife conservation. Tilburg University.
Burgess, G. (2016). Powers of persuasion?: Conservation communications, behavioural change and reducing demand for illegal wildlife products. Traffic Bulletin, 28(2), 65-73.

Capella, M. L., Taylor, C. R., \& Webster, C. (2008). The effect of cigarette advertising bans on consumption: A meta-analysis. Journal of Advertising, 37(2), 7-18.

Carins, J. E., \& Rundle-Thiele, S. R. (2014). Eating for the better: A social marketing review (2000-2012). Public Health Nutrition, 17(7), 1628-1639.

Carson-Chahhoud, K., Ameer, F., Sayehmeri, K., Hnin, K., Van Agteren, J. E. M., Sayehmiri, F., Brinn, M. P., Esterman, A. J., ... Smith, B. J. (2017). Mass media interventions for preventing smoking in young people. Cochrane Database of Systematic Reviews., 2017, CD001006.

Challender, D., Hinsley, A., \& Milner-Gulland, E. (2019). Inadequacies in establishing cites trade bans. Frontiers in Ecology and the Environment, 17(4), 199-200.

Chapman, S., Borland, R., Scollo, M., Brownson, R. C., Dominello, A., \& Woodward, S. (1999). The impact of smokefree workplaces on declining cigarette consumption in Australia and the United States. American Journal of Public Health, 89(7), 1018-1023.

Chaves, W. A., Valle, D. R., Monroe, M. C., Wilkie, D. S., Sieving, K. E., \& Sadowsky, B. (2018). Changing wild meat consumption: An experiment in the central amazon, Brazil. Conservation Letters, 11(2), e12391.

Christiano, A., \& Neimand, A. (2017). Stop raising awareness already. Stanford Social Innovation Review, 15(2), 34-41.

Cialdini, R. B. (2003). Crafting normative messages to protect the environment. Current Directions in Psychological Science, 12(4), 105-109.

Clarke, N., Pechey, E., Kosīte, D., König, L. M., Mantzari, E., Blackwell, A. K., \& Hollands, G. J. (2021). Impact of health warning labels on selection and consumption of food and alcohol products: Systematic review with meta-analysis. Health Psychology Review, 15(3), 430-453.

Clarke, S., Milner-Gulland, E. J., \& Bjørndal, T. (2007). Social, economic, and regulatory drivers of the shark fin trade. Marine Resource Economics, 22, 305-327.

Corepal, R., Tully, M. A., Kee, F., Miller, S. J., \& Hunter, R. F. (2018). Behavioural incentive interventions for health behaviour change in young people (5-18 years old): A systematic review and meta-analysis. Preventive Medicine, 110, 55-66.

Crayne, S., \& Haenlein, C. (2016). II. Poaching, wildlife trafficking and conflict. Whitehall Papers, 86(1), 38-57.

Cronin, D. T., Woloszynek, S., Morra, W. A., Honarvar, S., Linder, J. M., Gonder, M. K., ... Hearn, G. W. (2015). Long-term urban market dynamics reveal increased bushmeat carcass volume despite economic growth and proactive environmental legislation on bioko Island, Equatorial Guinea. PLoS One, 10(7), e0134464.

Cyranoski, D. (2020). Did pangolins spread the China coronavirus to people? Nature, 10. https://www.nature.com/articles/ d41586-020-00364-2

da Nóbrega Alves, R. R., da Silva Vieira, W. L., \& Santana, G. G. (2008). Reptiles used in traditional folk medicine: Conservation implications. Biodiversity and Conservation, 17(8), 20372049.

Davis, T., Goldwater, M. B., Ireland, M. E., Gaylord, N., \& Van Allen, J. (2017). Can you catch Ebola from a stork bite: 
Inductive reasoning influences generalization of perceived zoonosis risk. PLoS One, 12, e0186969.

Dee, L. E., Horii, S. S., \& Thornhill, D. J. (2014). Conservation and management of ornamental coral reef wildlife: Successes, shortcomings, and future directions. Biological Conservation, 169, 225-237.

Dotson, K. B., Dunn, M. E., \& Bowers, C. A. (2015). Stand-alone personalized normative feedback for college student drinkers: A meta-analytic review, 2004 to 2014. PLoS One, 10, e0139518.

Duffy, R., \& Humphreys, J. (2016). I. Poaching, wildlife trafficking and human security. Whitehall Papers, 86(1), 22-37.

Dulvy, N. K., Fowler, S. L., Musick, J. A., Cavanagh, R. D., Kyne, P. M., Harrison, L. R., et al. (2014). Extinction risk and conservation of the world's sharks and rays. eLife, 3, e00590.

Durkin, S., Brennan, E., \& Wakefield, M. (2012). Mass media campaigns to promote smoking cessation among adults: An integrative review. Tobacco Control, 21(2), 127-138.

Farrow, K., Grolleau, G., \& Ibanez, L. (2017). Social norms and proenvironmental behavior: A review of the evidence. Ecological Economics, 140, 1-13.

Feng, Y., Siu, K., Wang, N., Ng, K.-M., Tsao, S.-W., Nagamatsu, T., \& Tong, Y. (2009). Bear bile: Dilemma of traditional medicinal use and animal protection. Journal of Ethnobiology and Ethnomedicine, 5(1), 1-9.

Firestone, R., Rowe, C. J., Modi, S. N., \& Sievers, D. (2017). The effectiveness of social marketing in global health: A systematic review. Health Policy and Planning, 32(1), 110-124.

Foxcroft, D. R., Moreira, M. T., Santimano, N. M. A., \& Smith, L. A. (2015). Social norms information for alcohol misuse in university and college students. Cochrane Database of Systematic Reviews, 12, 1-138.

Frazer, K., Callinan, J. E., McHugh, J., van Baarsel, S., Clarke, A., Doherty, K., \& Kelleher, C. (2016). Legislative smoking bans for reducing harms from secondhand smoke exposure, smoking prevalence and tobacco consumption. Cochrane Database of Systematic Reviews, 2, 1-165.

Frazer, K., McHugh, J., Callinan, J. E., \& Kelleher, C. (2016). Impact of institutional smoking bans on reducing harms and secondhand smoke exposure. Cochrane Database of Systematic Reviews, 2, 1-165.

Graham-Rowe, D. (2011). Biodiversity: Endangered and in demand. Nature, 480(7378), S101-S103.

Gratwicke, B., Mills, J., Dutton, A., Gabriel, G., Long, B., Seidensticker, J., ... Zhang, L. (2008). Attitudes toward consumption and conservation of tigers in China. PLoS One, 3(7), e2544.

Green, K. M., Crawford, B. A., Williamson, K. A., \& DeWan, A. A. (2019). A meta-analysis of social marketing campaigns to improve global conservation outcomes. Social Marketing Quarterly, 25(1), 69-87.

Greenfield, S., \& Veríssimo, D. (2019). To what extent is social marketing used in demand reduction campaigns for illegal wildlife products?: Insights from elephant ivory and rhino horn. Social Marketing Quarterly, 25(1), 40-54.

Hefler, M., Liberato, S. C., \& Thomas, D. P. (2017). Incentives for preventing smoking in children and adolescents. Cochrane Database of Systematic Reviews, 2018, CD008645.

Heltberg, R. (1999). Trade bans and wildlife conservation: The case of African elephant ivory. Agrekon, 38, 405-413.
Henrich, J., Heine, S. J., \& Norenzayan, A. (2010). The weirdest people in the world? Behavioral and Brain Sciences, 33, 61-83.

Hopkins, D. P., Razi, S., Leeks, K. D., Kalra, G. P., Chattopadhyay, S. K., Soler, R. E., et al. (2010). Smokefree policies to reduce tobacco use: A systematic review. American Journal of Preventive Medicine, 38(2), S275-S289.

Hornik, J., Cherian, J., Madansky, M., \& Narayana, C. (1995). Determinants of recycling behavior: A synthesis of research results. The Journal of Socio-Economics, 24(1), 105-127.

Hughes, N., Arora, M., \& Grills, N. (2016). Perceptions and impact of plain packaging of tobacco products in low and middle income countries, middle to upper income countries and lowincome settings in high-income countries: A systematic review of the literature. BMJ Open, 6, e010391.

Hung, C.-L. (2017). A meta-analysis of the evaluations of social marketing interventions addressing smoking, alcohol drinking, physical activity, and eating (Unpublished Doctoral Dissertation). Indiana University.

Janssen, M. M., Mathijssen, J. J., van Bon-Martens, M. J., Van Oers, H. A., \& Garretsen, H. F. (2013). Effectiveness of alcohol prevention interventions based on the principles of social marketing: A systematic review. Substance Abuse Treatment, Prevention, and Policy, 8(1), 1-11.

Johnson, C. K., Hitchens, P. L., Evans, T. S., Goldstein, T., Thomas, K., Clements, A., et al. (2015). Spillover and pandemic properties of zoonotic viruses with high host plasticity. Scientific Reports, 5(1), 1-8.

Johnson, C. K., Hitchens, P. L., Pandit, P. S., Rushmore, J., Evans, T. S., Young, C. C., \& Doyle, M. M. (2020). Global shifts in mammalian population trends reveal key predictors of virus spillover risk. Proceedings of the Royal Society B, 287(1924), 1-10.

Kasterine, A., \& Lichtenstein, G. (2018). Trade in vicuña: Implications for conservation and rural livelihoods. International Trade Centre.

Kidd, L. R., Bekessy, S. A., \& Garrard, G. E. (2019a). Evidence is key for effective biodiversity communication. Trends in Ecology \& Evolution, 34, 693-694.

Kidd, L. R., Bekessy, S. A., \& Garrard, G. E. (2019b). Neither hope nor fear: Empirical evidence should drive biodiversity conservation strategies. Trends in Ecology \& Evolution, 34(4), 278-282.

Kidd, L. R., Garrard, G. E., Bekessy, S. A., Mills, M., Camilleri, A. R., Fidler, F., et al. (2019). Messaging matters: A systematic review of the conservation messaging literature. Biological Conservation, 236, 92-99.

Kolby, J. E. (2016). Pathways of amphibian chytrid fungus dispersal: Global biosecurity and conservation implications (Unpublished Doctoral Dissertation). James Cook University.

Kubacki, K., Rundle-Thiele, S., Pang, B., \& Buyucek, N. (2015). Minimizing alcohol harm: A systematic social marketing review (2000-2014). Journal of Business Research, 68(10), 2214-2222.

Kurland, J., Pires, S. F., McFann, S. C., \& Moreto, W. D. (2017). Wildlife crime: A conceptual integration, literature review, and methodological critique. Crime Science, 6(1), 1-15.

Leader-Williams, N. (2014). Regulation and protection: Successes and failures in rhinoceros conservation. Routledge.

Lee, J. G., Chng, S. C., \& Eaton, J. A. (2016). Conservation strategy for southeast asian songbirds in trade. Wildlife Reserves Singapore/TRAFFIC. 1-31. 
Leigh, A. (2018). Randomistas: How radical researchers are changing our world. Yale University Press.

Lu, H., McComas, K. A., Buttke, D. E., Roh, S., Wild, M. A., \& Decker, D. J. (2017). One health messaging about bats and rabies: How framing of risks, benefits and attributions can support public health and wildlife conservation goals. Wildlife Research, 44(3), 200-206.

MacFarlane, D., \& Rocha, R. (2020). Guidelines for communicating about bats to prevent persecution in the time of covid-19. Biological Conservation, 248, 108650.

MacFarlane, D., Hurlstone, M. J., \& Ecker, U. K. (2021). Countering demand for ineffective health remedies: Do consumers respond to risks, lack of benefits, or both? Psychology \& Health, 36(5), 593-611.

MacFarlane, D., Hurlstone, M. J., \& Ecker, U. K. (2020). Protecting consumers from fraudulent health claims: A taxonomy of psychological drivers, interventions, barriers, and treatments. Social Science \& Medicine, 259, 112790.

MacMillan, D. C., \& Challender, D. W. (2014). Changing behavior to tackle the wildlife trade. Frontiers in Ecology and Environment, 12(4), 203.

Mantzari, E., Vogt, F., Shemilt, I., Wei, Y., Higgins, J. P., \& Marteau, T. M. (2015). Personal financial incentives for changing habitual health-related behaviors: A systematic review and meta-analysis. Preventive Medicine, 75, 75-85.

Marteau, T. M., Hollands, G. J., \& Fletcher, P. C. (2012). Changing human behavior to prevent disease: The importance of targeting automatic processes. Science, 337(6101), 1492-1495.

Mason, C. F., Bulte, E. H., \& Horan, R. D. (2012). Banking on extinction: Endangered species and speculation. Oxford Review of Economic Policy, 28(1), 180-192.

Maxwell, S. L., Fuller, R. A., Brooks, T. M., \& Watson, J. E. (2016). Biodiversity: The ravages of guns, nets and bulldozers. Nature News, 536, 143-145.

McAfee, D., \& Connell, S. D. (2019). Balancing the benefits of optimism and pessimism in conservation: A response to kidd, bekessy, and garrard. Trends in Ecology \& Evolution, 34(8), 692-693.

McEvoy, J. F., Connette, G., Huang, Q., Soe, P., Pyone, K. H. H., Valitutto, M., et al. (2019). Two sides of the same coinwildmeat consumption and illegal wildlife trade at the crossroads of Asia. Biological Conservation, 238, 108197.

McNeill, A., Gravely, S., Hitchman, S. C., Bauld, L., Hammond, D., \& Hartmann-Boyce, J. (2017). Tobacco packaging design for reducing tobacco use. Cochrane Database of Systematic Reviews, 2017, CD011244.

Michie, S., Van Stralen, M. M., \& West, R. (2011). The behaviour change wheel: A new method for characterising and designing behaviour change interventions. Implementation Science, 6(1), $1-12$.

Monárrez-Espino, J., Liu, B., Greiner, F., Bremberg, S., \& Galanti, R. (2014). Systematic review of the effect of pictorial warnings on cigarette packages in smoking behavior. American Journal of Public Health, 104, e11-e30.

Monson, E., \& Arsenault, N. (2017). Effects of enactment of legislative (public) smoking bans on voluntary home smoking restrictions: A review. Nicotine \& Tobacco Research, 19(2), 141-148.

Moodie, C., Stead, M., Bauld, L., McNeill, A., Angus, K., Hinds, K., ... O'Mara-Eves, A. (2012). Plain tobacco packaging: A systematic review (Technical Report).
Mosdøl, A., Lidal, I. B., Straumann, G. H., \& Vist, G. E. (2017). Targeted mass media interventions promoting healthy behaviours to reduce risk of non-communicable diseases in adult, ethnic minorities. Cochrane Database of Systematic Reviews, 2017, CD011683.

Moyle, B. (2009). The black market in China for tiger products. Global Crime, 10(1-2), 124-143.

Myers, R. A., Baum, J. K., Shepherd, T. D., Powers, S. P., \& Peterson, C. H. (2007). Cascading effects of the loss of apex predatory sharks from a coastal ocean. Science, 315(5820), 1846-1850.

Newman, C., Macdonald, D., \& Zhou, Y. (2014). Pangolin: Illegal medicine trade threatens these scaly mammals with extinction. The Conversation, e33817. https://theconversation.com/pangolin-illegalmedicine-trade-threatens-these-scaly-mammals-with-extinction33817

Ng, N. (2013). China bans shark fin dishes at official banquets. CNN. https://edition.cnn.com/2013/12/09/world/asia/chinaban-shark-fin/index.html

Noar, S. M., Francis, D. B., Bridges, C., Sontag, J. M., Ribisl, K. M., \& Brewer, N. T. (2016). The impact of strengthening cigarette pack warnings: Systematic review of longitudinal observational studies. Social Science \& Medicine, 164, 118-129.

Noar, S. M., Hall, M. G., Francis, D. B., Ribisl, K. M., Pepper, J. K., \& Brewer, N. T. (2016). Pictorial cigarette pack warnings: A meta-analysis of experimental studies. Tobacco Control, 25(3), 341-354.

Pearce, D. W., \& Turner, R. K. (1990). Economics of natural resources and the environment. JHU Press.

Peeters, M., Courgnaud, V., Abela, B., Auzel, P., Pourrut, X., Bibollet-Ruche, F., et al. (2002). Risk to human health from a plethora of simian immunodeficiency viruses in primate bushmeat. Emerging Infectious Diseases, 8(5), 451-457.

Peters, G.-J. Y., Ruiter, R. A., \& Kok, G. (2013). Threatening communication: A critical re-analysis and a revised meta-analytic test of fear appeal theory. Health Psychology Review, 7, S8-S31.

Prestwich, A., Kellar, I., Conner, M., Lawton, R., Gardner, P., \& Turgut, L. (2016). Does changing social influence engender changes in alcohol intake? A meta-analysis. Journal of Consulting and Clinical Psychology, 84(10), 845-860.

Pynegar, E. L., Gibbons, J. M., Asquith, N. M., \& Jones, J. P. (2021). What role should randomized control trials play in providing the evidence base for conservation? Oryx, 55(2), 235-244.

Quentin, W., Neubauer, S., Leidl, R., \& König, H.-H. (2007). Advertising bans as a means of tobacco control policy: A systematic literature review of time-series analyses. International Journal of Public Health, 52(5), 295-307.

Rare, \& Team, T. B. I. (2019). Behavior change for nature: A behavioral science toolkit for practitioners.

Rode, J., Gómez-Baggethun, E., \& Krause, T. (2015). Motivation crowding by economic incentives in conservation policy: A review of the empirical evidence. Ecological Economics, 117, 270-282.

Rosen, G. E., \& Smith, K. F. (2010). Summarizing the evidence on the international trade in illegal wildlife. EcoHealth, 7, 24-32.

Rossen, I., Hurlstone, M. J., \& Lawrence, C. (2016). Going with the grain of cognition: Applying insights from psychology to build support for childhood vaccination. Frontiers in Psychology, 7, 1483. 
Salazar, G., Mills, M., \& Veríssimo, D. (2019). Qualitative impact evaluation of a social marketing campaign for conservation. Conservation Biology, 33(3), 634-644.

Scheele, B. C., Pasmans, F., Skerratt, L. F., Berger, L., Martel, A., Beukema, W., et al. (2019). Amphibian fungal panzootic causes catastrophic and ongoing loss of biodiversity. Science, 363(6434), 1459-1463.

Scholes-Balog, K. E., Heerde, J. A., \& Hemphill, S. A. (2012). Alcohol warning labels: Unlikely to affect alcohol-related beliefs and behaviours in adolescents. Australian and New Zealand Journal of Public Health, 36(6), 524-529.

Schultz, P., \& Kaiser, F. G. (2012). Promoting pro-environmental behavior. In D. C. Susan (Ed.), The Oxford handbook of environmental and conservation psychology. Oxford University Press.

Schultz, P. W., Nolan, J. M., Cialdini, R. B., Goldstein, N. J., \& Griskevicius, V. (2018). The constructive, destructive, and reconstructive power of social norms: Reprise. Psychological Science, 13, 249-254.

Sheeran, P., Harris, P. R., \& Epton, T. (2014). Does heightening risk appraisals change people's intentions and behavior?: A metaanalysis of experimental studies. Psychological Bulletin, 140(2), 511-543.

Siegfried, N., Pienaar, D. C., Ataguba, J. E., Volmink, J., Kredo, T., Jere, M., \& Parry, C. D. (2014). Restricting or banning alcohol advertising to reduce alcohol consumption in adults and adolescents. Cochrane Database of Systematic Reviews, CD010704. $11,1-49$.

Smith, R. J., Salazar, G., Starinchak, J., Thomas-Walters, L. A., \& Veríssimo, D. (2020). Social marketing and conservation. In Conservation Research, Policy and Practice (pp. 309-321). Cambridge Core.

Snyder, L. B., Hamilton, M. A., Mitchell, E. W., KiwanukaTondo, J., Fleming-Milici, F., \& Proctor, D. (2004). A metaanalysis of the effect of mediated health communication campaigns on behavior change in the United States. Journal of Health Communication, 9, 71-96.

Stead, M., Gordon, R., Angus, K., \& McDermott, L. (2007). A systematic review of social marketing effectiveness. Health Education, 107, 126-191.

Sturgis, P., \& Allum, N. (2004). Science in society: Re-evaluating the deficit model of public attitudes. Public Understanding of Science, 13(1), 55-74.

Suwannarong, K., \& Schuler, S. (2016). Bat consumption in Thailand. Infection Ecology \& Epidemiology, 6, 29941.

Tannenbaum, M. B., Hepler, J., Zimmerman, R. S., Saul, L., Jacobs, S., Wilson, K., \& Albarracín, D. (2015). Appealing to fear: A meta-analysis of fear appeal effectiveness and theories. Psychological Bulletin, 141(6), 1178-2004.

Thomas-Walters, L., Hinsley, A., Bergin, D., Burgess, G., Doughty, H., Eppel, S., ... \& Veríssimo, D. (2021). Motivations for the use and consumption of wildlife products. Conservation Biology, 35(2), 483-491.

Trieu, K., McMahon, E., Santos, J. A., Bauman, A., Jolly, K.-A., Bolam, B., \& Webster, J. (2017). Review of behaviour change interventions to reduce population salt intake. International
Journal of Behavioral Nutrition and Physical Activity, 14(1), 1-15.

Truong, V. D., Dang, N. V., \& Hall, C. M. (2016). The marketplace management of illegal elixirs: Illicit consumption of rhino horn. Consumption Markets \& Culture, 19(4), 353-369.

Vallianos, C., Sherry, J., Hoford, A., \& Baker, J. (2018). Sharks in crisis: Evidence of positive behavioral change in China as new threats emerge. WildAid.

Veríssimo, D., \& Wan, A. K. (2019). Characterizing efforts to reduce consumer demand for wildlife products. Conservation Biology, 33(3), 623-633.

Watts, J. (2011). Cure for cancer rumour killed off Vietnam's rhinos. The Guardian, 25. https:/www.theguardian.com/environment/ 2011/nov/25/cure-cancer-rhino-horn-vietnam

Werb, D., Mills, E. J., DeBeck, K., Kerr, T., Montaner, J. S., \& Wood, E. (2011). The effectiveness of anti-illicit-drug publicservice announcements: A systematic review and meta-analysis. Journal of Epidemiology and Community Health, 65(10), 834-840.

Whitcraft, S., Hofford, A., Hilton, P., O'Malley, M., Jaiteh, V., \& Knights, P. (2014). Evidence of declines in shark fin demand. China.

Wittig, T. (2016). IV. Poaching, wildlife trafficking and organised crime. Whitehall Papers, 86(1), 77-101.

Wood, A. M., Brown, G. D., \& Maltby, J. (2012). Social norm influences on evaluations of the risks associated with alcohol consumption: Applying the rank-based decision by sampling model to health judgments. Alcohol and Alcoholism, 47(1), 57-62.

Wright, A. J., Veríssimo, D., Pilfold, K., Parsons, E., Ventre, K., Cousins, J., ... McKinley, E. (2015). Competitive outreach in the 21st century: Why we need conservation marketing. Ocean \& Coastal Management, 115, 41-48.

Wright, E. M., Bhammar, H. M., Gonzalez Velosa, A. M., \& Sobrevila, C. (2016). Analysis of international funding to tackle illegal wildlife trade. World Bank Group.

Zhao, H. (2020). Covid-19 drives new threat to bats in China. Science, 367(6485), 1436-1436.

\section{SUPPORTING INFORMATION}

Additional supporting information may be found in the online version of the article at the publisher's website.

How to cite this article: MacFarlane, D., Hurlstone, M. J., Ecker, U. K. H., Ferraro, P. J., van der Linden, S., Wan, A. K. Y., Veríssimo, D., Burgess, G., Chen, F., Hall, W., Hollands, G. J., \& Sutherland, W. J. (2022). Reducing demand for overexploited wildlife products: Lessons from systematic reviews from outside conservation science. Conservation Science and Practice, e627. https://doi.org/10.1111/csp2.627 